\title{
The study of the responsibility of persons who don't have children as a promising area of psychological and pedagogical support of future parents
}

\author{
Marina Gremyachih* \\ Ryazan State University named for S.A. Yesenina, 390000 Ryazan, Russia
}

\begin{abstract}
The article describes the problem of psychological support and training for such an untraditional category of people for a customized education system as people expecting or planning to have a child. The results of the study of responsibility as a personal property in the context of parent-child relationships are presented; in particular, the level of severity of the responsibility variables determined using the "Test of liability judgments" by A.I. Krupnova. The primary data underwent mathematical processing, which made it possible to determine the normality of the distribution of the sample, and subsequently establish statistically significant differences between harmonic and inharmonic responsibility variables. By mathematical processing of the data, the severity levels of the variables of the target, motivational, cognitive, productive, dynamic, emotional, regulatory and evaluative-reflexive components of responsibility are determined and the percentage of persons from the surveyed sample who have high, above average, average, below average and low levels is revealed parameters. Interpretation of the data obtained during the study, their analysis allow us to determine the features of the structure of responsibility of people who are expecting or planning to have a baby, as well as draw conclusions about the features of its development.
\end{abstract}

In recent years the modern educational environment has undergone significant changes. They affect both the substantive and organizational components of the educational process. It is generally accepted that students and teachers are directly included in the training system; In certain circumstances, parents / significant relatives and other groups of people (assistants, medical workers, etc.) are added to these participants in the educational process. The modern system of psychological and pedagogical assistance assumes the function of accompanying all of the above categories. The need for focused, methodical work with parents is a universally recognized fact. This direction of modern educators and psychologists' work has many variations, which, in our opinion, is quite justified, since successful parent-child relationships and the parent's involvement in the education system are very important components of the harmonious development of the child's personality. Many parents, feeling their incompetence in some aspects of raising children, turn to

\footnotetext{
* Corresponding author: marinagrem@mail.ru
} 
specialists for help, look for appropriate psychological and pedagogical literature, and some go to study themselves to fill the existing lack of knowledge. Currently, the number of married couples is increasing, which even at the stage of pregnancy or even when planning a baby begin to think about how their relationship with future children will develop. Due to this trend, more and more medical and pedagogical organizations are taking on the responsibility of accompanying those planning a birth of a child, in many aspects this process consists of training and psychological support. All of the above indicates that the modern education system, and particularly its psychological service, is forced to develop more and more ways and methods of working with various categories of participants in the educational process, and particularly with parents who change their role functions to student ones when embedded in the educational process.

Inspite of the large number of studies devoted to the study of family relations, such an importantaspect as responsibility in the context of parent-child relations remains poorly understood.

Responsibility is a personality trait that can be found in almost all activities. To a greater or lesser extent, responsibility is characteristic of each person. Society makes the individual demand to be responsible, otherwise the individual cannot become socially successful, as it loses trust from others. It should be assumed that the institution of the family is no exception, and the manifestation of responsibility in family relations is inevitable. In the course of studying the indicated psychological problem and organizing the study, we put forward the assumption that responsibility affects not only family relations, but also, being a systematic personality trait, can become a predictor of dominant parenting styles.

In our study, we divided the respondents into four identical groups:

- persons without children;

- a person with a short parenthood (the age of the oldest / only child is from 0 to 3 years);

- a person with an average length of parenthood (the age of the oldest / only child is from 3 to 11 years);

- a person with a long record of parenthood (the age of the oldest / only child is from 11 years to 21 years).

This article describes the results of a study of people without children. This subgroup has aroused our research interest, since we assume that, based on a study of the responsibility of people with different lengths of parenthood, as well as those without children, it is possible to distinguish groups with similar indicators of responsibility, which, in turn, will have connections with those or other components of parenting styles. This study will allow us to develop recommendations for building a favorable relationship with a future child.

Responsibility was studied by us in the framework of the concept of a multidimensional-functional model of the organization of personality properties by A.I. Krupnova. According to this theory, the above personality trait is considered as a system of meaningful (goal-oriented, motivational, cognitive, productive) and instrumental-style (dynamic, emotional, regulatory and reflective-evaluative) components $[1,2]$.

In modern scientific knowledge, responsibility is studied depending on the social status and activity of the subject (Antonov A.N., Bogachev S.A., Vorobyov V.I., Ganina N.A., Golutvin A.V., Zeer E.F., Ilyin V.V., Kapto A.S., Kosarev I.I., Lenk G., Novikov N.V., Oduev S.F., Turenko V.V., etc.).

In foreign psychology, responsibility research is conducted in various fields (CharmsR., DavisW.L., GinsbergM., HiederF., KellyH.H., Kohlberg L., Lowe CA, MaclverR.M., MedwayF.Y., Piaget J., ThompsonK. and etc.). 
The study of responsibility in modern research is based on the principles of the unity of personality and activity (Abulkhanova-Slavskaya K.A., Leontyev A.N., Lomov B.F., Petrovsky A.V., Reinvald N.I. and others); a systematic and holistic approach to the study of personality and individuality (Abulkhanova-Slavskaya K.A., Ananyev B.G., Antsyferova L.I., Golubeva E.A., Lomov B.F., Nebylitsyn V.D., Petrovsky A .V., Rheinwald N.I., Feldstein D.I. et al.).

Responsibility in the context of parent-child relationships is poorly understood, however, almost all authors working in this direction confirm the significance of this personality trait, for example, in the works of M. Ermikhina. responsibility is an integral part of informed parenthood [3].

Of the greatest value for our research is the concept of a multidimensional-functional organization of personality and individuality properties, developed by Krupnov A.I. [3,4]. It is worth noting that it is applicable to the study of various personality traits, for example, industriousness, curiosity, sociability, etc. The questions of responsibility study in the framework of the above-mentioned approach were dealt with by Bessmertnaya S.V., Bespalova T.M., Tenyaeva O.V., Sedova I.V.

In the work of Bespalova T.M. responsibility is defined as the moral-volitional property of a person, formed in the process of activity and education. This definition is considered by us as a key one, in the further description of the characteristics of the responsibility of persons with various lengths of parenthood / absence of length of service, we rely on it [4].

To study the responsibility of persons without children, we used the "Test of liability judgments" developed by A.I. Krupnov. This technique allows us to consider responsibility as a system of meaningful and instrumental-style components. Each of these blocks includes four components, which, in turn, are divided into two bipolar variables: harmonic and agarmonic. Good development and prevalence of harmonic variables in the structure of individual responsibility indicates strength, stability, diversity of aspirations, and agarmonic variables manifest themselves in instability, weakness, and abandonment of their own goals $[5]$.

The use of the non-parametric Z-Kolmogorov-Smirnov criterion to determine the normality of the distribution allowed the use of the Student t-test parametric criterion to identify the significance of differences between harmonic and agharmonic responsibility variables. The results of the above mathematical processing are shown in table 1 .

The substantial-semantic block of responsibility is not formed harmoniously. Despite the predominance of harmonic variables in the motivational and cognitive components, the target component is dominated by personally significant goals that relate to agarmonic variables. The motivational component is dominated by sociocentric motives, i.e. the studied group of people is fully aware of itself as a part of society and is motivated by the preservation of public well-being. There were no significant differences between the variables of the productive component.

It has been statistically confirmed that meaningfulness prevails in persons without children in the cognitive component, which means that they well understand the meaning and nature of responsible behavior. At the same time, the predominance of the agharmonic variable of the target component indicates the prevalence of their own, subjectively significant goals: for example, achieving material well-being and gaining independence.

The instrumental-style block in people without children is formed quite harmoniously. This is indicated by the predominance of harmonic variables.

It has been statistically confirmed that meaningfulness prevails in persons without children in the cognitive component, which means that they well understand the meaning and nature of responsible behavior. At the same time, the predominance of the agharmonic variable of the target component indicates the prevalence of their own, subjectively significant goals: for example, achieving material well-being and gaining independence. 
The instrumental-style block in people without children is formed quite harmoniously. This is indicated by the predominance of harmonic variables.

Statistical confirmation of the significance of the differences was obtained by the variables of the dynamic component, which characterizes this group of respondents as proactive, energetic, inclined to conscientiously fulfill a responsible assignment. The prevalence of internality in the regulatory component indicates a willingness to take responsibility for their behavior and social obligations to society, awareness of their own role in establishing and maintaining interpersonal relationships.

Table 1. Features of responsibility of persons without children

\begin{tabular}{|c|c|c|c|c|c|}
\hline Block & Component & Variable & $\begin{array}{l}\text { Average } \\
\text { result }\end{array}$ & $\begin{array}{l}\mathrm{t}- \\
\text { criteria }\end{array}$ & $\begin{array}{l}\text { Level of } \\
\text { significance } \\
\text { of } \\
\text { differences }\end{array}$ \\
\hline \multirow{8}{*}{ Meaningful } & \multirow[t]{2}{*}{ Target } & $\begin{array}{l}\text { Socially } \\
\text { significant goals }\end{array}$ & 26 & \multirow[t]{2}{*}{$-6,403$} & \multirow[t]{2}{*}{0,000} \\
\hline & & $\begin{array}{l}\text { Personally } \\
\text { significant goals }\end{array}$ & 34 & & \\
\hline & \multirow[t]{2}{*}{ Motivational } & Sociocentricity & 32 & \multirow[t]{2}{*}{9,336} & \multirow[t]{2}{*}{0,000} \\
\hline & & Self-centeredness & 20 & & \\
\hline & \multirow[t]{2}{*}{ Cognitive } & Meaningfulness & 35 & \multirow[t]{2}{*}{15,646} & \multirow[t]{2}{*}{0,000} \\
\hline & & Awareness & 10 & & \\
\hline & \multirow[t]{2}{*}{ Productive } & Objectivity & 32 & \multirow[t]{2}{*}{$-1,953$} & \multirow[t]{2}{*}{0,057} \\
\hline & & Subjectivity & 34 & & \\
\hline \multirow{8}{*}{$\begin{array}{l}\text { Instrumental } \\
\text { Style }\end{array}$} & \multirow[t]{2}{*}{ Dynamic } & Ergidity & 26 & \multirow[t]{2}{*}{5,698} & \multirow[t]{2}{*}{0,000} \\
\hline & & Aerigicity & 14 & & \\
\hline & \multirow[t]{2}{*}{ Emotional } & Strenichnost & 29 & \multirow[t]{2}{*}{1,051} & \multirow[t]{2}{*}{0,298} \\
\hline & & Asthenicity & 27 & & \\
\hline & \multirow[t]{2}{*}{ Regulatory } & Internality & 36 & \multirow[t]{2}{*}{14,070} & \multirow[t]{2}{*}{0,000} \\
\hline & & Externalism & 18 & & \\
\hline & \multirow[t]{2}{*}{$\begin{array}{l}\text { Reflective } \\
\text { assessment }\end{array}$} & $\begin{array}{l}\text { Operational } \\
\text { difficulties }\end{array}$ & 19 & \multirow[t]{2}{*}{$-0,165$} & \multirow[t]{2}{*}{0,869} \\
\hline & & $\begin{array}{l}\text { Emotional and } \\
\text { personal } \\
\text { difficulties }\end{array}$ & 19 & & \\
\hline
\end{tabular}

The statistical significance of differences in the variables of emotional and reflectiveevaluative components was not confirmed.

The identification of the levels of severity of the responsibility variables using the statistical standard deviation method (standard deviation - sigma) made it possible to conduct a more detailed analysis of the formation of various variables of the responsibility structure (Table 2).

Table 2. The number of persons (in\%) who do not have children, with different levels of severity of responsibility variables

\begin{tabular}{|l|c|c|c|c|c|}
\hline \multirow{2}{*}{ Variable } & \multicolumn{4}{|c|}{ Severity } \\
\cline { 2 - 5 } & High & $\begin{array}{c}\text { Above } \\
\text { average }\end{array}$ & Medium & $\begin{array}{c}\text { Low } \\
\text { average }\end{array}$ & Low \\
\hline
\end{tabular}




\begin{tabular}{|l|c|c|c|c|c|}
\hline Socially significant goals & 8 & 18 & 54 & 12 & 8 \\
\hline $\begin{array}{l}\text { Personally significant } \\
\text { goals }\end{array}$ & 8 & 10 & 62 & 10 & 10 \\
\hline Sociocentricity & 8 & 12 & 64 & 6 & 10 \\
\hline Self-centeredness & 12 & 12 & 60 & 12 & 4 \\
\hline Meaningfulness & 8 & 14 & 62 & 6 & 10 \\
\hline Awareness & 8 & 8 & 72 & 12 & 0 \\
\hline Objectivity & 4 & 22 & 56 & 12 & 6 \\
\hline Subjectivity & 6 & 6 & 74 & 12 & 2 \\
\hline Ergidity & 8 & 12 & 66 & 8 & 6 \\
\hline Aerigicity & 12 & 14 & 58 & 8 & 8 \\
\hline Strenichnost & 8 & 8 & 64 & 12 & 8 \\
\hline Asthenicity & 6 & 12 & 62 & 12 & 8 \\
\hline Internality & 10 & 4 & 60 & 22 & 4 \\
\hline Externalism & 6 & 12 & 64 & 6 & 12 \\
\hline Operational difficulties & 10 & 4 & 70 & 10 & 6 \\
\hline $\begin{array}{l}\text { Emotional and personal } \\
\text { difficulties }\end{array}$ & 4 & 12 & 62 & 16 & 6 \\
\hline
\end{tabular}

During describing of the obtained results, it should be noted the variables with the highest percentages. As can be seen from the table above, the vast majority of respondents have an average level of severity of all responsibility variables.

In the content-semantic block, a sufficiently large number of respondents have high and above average levels for such variables as "socially significant goals" (total score of 26\%), "egocentricity" (total score of 24\%) and "objectivity" (total score of $26 \%$ ). Low and below average levels can often be observed when considering variables such as "socially significant goals" (total score of 20\%) and "personality-significant goals" (total score of $20 \%)$.

High indicators on a scale of "egocentricity" indicate a pronounced desire to show their abilities and will, to use their potential for personal goals. High and above average levels in the variable "subjectivity" are characteristic of people who primarily use responsibility in the subject-activity sphere.

High scores on the scale of "socially significant goals" indicate clearly defined goals, objectives and intentions, manifestations of responsibility in social activities. These people strive to achieve recognition both in reference groups and in wider social circles. The level is below average, and even lower level indicates a lack of awareness, or the devaluation of social functioning and the importance of responsibility in interpersonal interaction. The low level of formation of the variable "personally significant goals" can be an indicator of asceticism, as well as indifference to one's own successes and achievements. It should be noted that the high frequency of occurrence of these bipolar characteristics among people without children, once again confirms the lack of formation of a meaningful block of responsibility for this group of respondents.

When analyzing the indicators of the instrumental-style block, one can note a large number of respondents with high scores on the "aerogicity" scale (total indicator 26\%); in other words, - with no stability and a small desire for responsibility. A higher percentage of occurrence of low and lower than average levels can be observed on the scale of "internality" (total indicator 26\%). Respondents who fall into this category are not ready to take responsibility for what is happening.

Based on all the above data, we can conclude that the meaningful block of responsibility in people without children is not formed harmoniously, and the instrumental-style block is harmonious. In other words, this category of people has sufficient resources and skills to 
implement responsibility, but there is not enough meaningfulness to harmonize the studied property. According to the level of expression of responsibility variables, respondents with high and low levels were divided into approximately the same groups. Nevertheless, based on the severity of ergism, which indicates the strength of aspiration and stability of the manifestation of responsibility, it can be concluded that the number of more responsible people to some extent exceeds the less responsible. The data obtained can be used for the work of a psychologist accompanying persons who are waiting for or planning a child. Optimization of the level of responsibility and harmonization of the structure of this personality trait will stimulate the personal growth of future parents, which is one of the leading areas of psychological and pedagogical support for this category of people. This stage of work with the parent community is the prevention of the risk of family distress; it helps to avoid possible difficulties associated with raising children, even at the planning and expectation stage of the child.

\section{References}

1. A.I. Krupnov, Diagnosis of personality and personality traits (Youth Institute, Moscow, 1993)

2. A.I. Krupnov, Systemic Diagnostics and Correction of Sociability: Monograph (RUDN University, Moscow, 2007)

3. M.O. Ermikhina, Psychological support of the personality in the pedagogical process (Kurgan state University, Kurgan, 2002)

4. T.M. Bespalova, Psychological and pedagogical search, 24, 149-155 (2012)

5. S.I. Kudinov, S.S. Kudinov, I.V. Sedova, Acmeology, 2 (58), $72-78$ (2016) 